\title{
Sexual Dysfunction Among Cancer Survivors
}

\author{
Atara Ntekim \\ Department of Radiation Oncology, College of Medicine, University of Ibadan \\ Nigeria
}

\section{Introduction}

"Sexual and reproductive health and wellbeing are essential if people are to have responsible, safe and satisfying sexual lives. Sexual health requires a positive approach to human sexuality and an understanding of the complex factors that shape human sexual behaviour. These factors affect whether the expression of sexuality leads to sexual health and well- being or to sexual behaviour that put people at risk or make them vulnerable to sexual and reproductive ill- health. Health program managers, policy - makers and care providers need to understand and promote the potentially positive role sexuality can play in peoples' lives and to build health services that can promote sexually health societies." (WHO 2006)

There is increasing number of cancer survivors worldwide. A lot of them experience sexual dysfunction for a long time which can last beyond ten years post treatment. Sexual dysfunction can occur as a result of any aspect of cancer and cancer treatment. Sexual functioning and/or satisfaction have been found to be of concern to many cancer survivors. Sexual function can be affected by physical or emotional trauma especially if the genitals are affected and can adversely affect the quality of life of the patients. Sexual dysfunction includes erectile dysfunction in males and disruption in the sexual response cycle (sexual desire, excitement, arousal, orgasm and resolution) and dyspareunia in women. There are differences in the pattern of sexual dysfunction between males and females as females may be able to cope better than males emotionally. Bonini-Colmano et al. (2007) noted that malignant diseases have a strong influence in quality of life, sexuality being one of the most affected variables. In their study to determine the prevalence of sexual dysfunction in a cohort of patients with cancer and its relationship with the following: pain, fatigue, nausea, vomiting, mechanisms of adaptation to stress, anxiety and depression, questionnaires were used which included treatment, adverse events, Zimong and Snaith depression and anxiety scale, sexual dysfunction questionnaire, coping strategies of Tobin David, Hopwood body image scale and the analogical visual test for pain evaluation. Sixty four patients were evaluated. Seventy two percent were women and median age was 50 years. Libido was absent in $50 \%$; this was associated with gender (better in men; $p=0,05$ ) and the presence of pain $(p=0,05)$ and fatigue $(p=0,05)$ but not with age. All patients who had intact libido also had arousal and orgasms; this was more prevalent in men than in women and in subjects younger than 60 years. Arousal was absent in $47 \%$ of cases. Forty four percent of men had erectile dysfunction; this was present in all patients older than 60 years. Frequency of 
intercourses was decreased in $75 \%$. Fifty eight percent of patients said that their sexuality was better before the diagnosis of their disease. Interestingly, $85 \%$ didn't talk to their doctors about their sexual problems. The study concluded that one out of 2 patients had sexual dysfunction, predominantly women and that sexuality was affected mainly by pain and fatigue. Although normal libido was present in all ages, subjects older than 60 years had less arousal and orgasms.

The age of the patients also determines the extent of the problem. Testicular cancer for example is more common among youths. At this age group, the patients are either about to get married or in early stage of their family life. Sexual problem at this stage can be grievous and very traumatizing. Prostate cancer on the other hand is common among the elderly who would have completed their family and may be more concerned about survival than sexual activities. Sexual issues may therefore not be of prominence among this age group. The site of the disease also determines the extent of the problem. A male patient with cancer of the penis treated with amputation of the penis will experience more sexual dysfunction than a patient with testicular cancer who has a testicle removed. In females, a breast cancer patient who had the affected breast removed (mastectomy) will experience more sexuality issues than a female counterpart who had only the lump removed (lumpectomy). (Ofman 1995) Likewise, a female patient treated for cervical cancer with radiotherapy will experience more sexual problems than a female patient treated for head and neck cancer with radiotherapy.

Survivors of cancer of various anatomical sites experience various degrees of sexual dysfunction. After treatment, approximately $20 \%$ to $30 \%$ of breast cancer survivors, $80 \%$ of prostate cancer survivors, $37 \%$ of Hodgkin's survivors, and $58 \%$ of head and neck cancer survivors report sexual difficulties. (Elyse et al., 2009) Changes in body image, pain, and loss of desire result from both cancer and its treatment; long-term physical and psychological side effects from cancer treatments can affect sexual functioning. Long-term psychological responses, such as depression and anxiety about cancer, may alter the survivor's ability for intimacy and sexuality.

Sexual dysfunction therefore is an important issue that affects many cancer survivors who are increasingly being cared for by health personnel. It is noted that sexual dysfunction among these group of patients is never addressed by most of their care givers during follow up management. Many effective behavioural and pharmacological treatments for sexual dysfunction exist. However, to identify cancer survivors who may benefit from these treatments, conversations about sexual dysfunctions must be initiated. Survivors express a desire to be able to discuss sexual issues with medical professionals. However, there are barriers to these conversations for both patients and physicians. A public opinion poll of 500 adults in the United States showed that $85 \%$ would be willing to talk to their physicians if they had a sexual problem. However, $71 \%$ did not think that their physicians would be responsive or helpful, and $68 \%$ were concerned that their physicians would be uncomfortable and also reports from some studies found that lack of knowledge, expertise, time, and comfort are barriers to these conversations. (Bober et al., 2009)

\section{Aim}

The aim of this chapter is to highlight sexual health issues among cancer survivors so that clinicians and care givers can be able to predict this sequel and incorporate measures as early as possible towards prevention, reduction, assessment using appropriate instruments 
and management of this important condition among patients thereby improving the sexuality aspect of their quality of life.

\section{Methods}

Available literature (hard and electronic copies) including the authors work relevant to this topic were consulted and evaluated. The sexuality component of the authors work on quality of life of head and neck cancer patients seen at The Radiotherapy Department, University College Hospital, Ibadan Nigeria (yet to be published) is reported .

\section{Findings and discussion}

The findings together with relevant discussion pertaining to common group of malignancies are as follows:

\subsection{Female breast cancer survivors}

Breast cancer is a common cancer among women and survival has increased over time especially if treatment is commenced early. Five year survival has reached about $97 \%$ especially in the developed countries with early disease. (Thors et al., 2001) This implies that a lot of women will live long and are likely to experience sexual dysfunction. With breast cancer the term "survivors" is used here to refer to women who have completed surgery, chemotherapy/hormonal and/or radiation therapy for the treatment of breast cancer. Most breast cancer survivors experience about $15 \%$ reduction in sexual satisfaction after treatment (Bukovic et al., 2005). Approximately 20-30\% of breast cancer survivors experience sexual problems including general sexual disruption, decreased frequency of intercourse, and difficulties reaching orgasm that may persist 20 years post-treatment (Alfano et al., 2007).The reported prevalence of this problem varies greatly, partly due to the various methods and instruments used in their assessment. In terms of specific sexual difficulties, the most common current symptoms reported in this study were absence of sexual desire $(48 \%)$, reduced sexual desire (64\%), anorgasmia (44\%), lubrication difficulties $(42 \%)$, and dyspareunia (38\%) while two or more problems were present in about $97 \%$ of the participants. These findings show that certain problems appear to be related to the desire stage of sexual activity (e.g. loss of interest in sex), while others appear to be related to the arousal stage (e.g. lubrication difficulties) and the orgasmic stage (e.g. anorgasmy).

In a study among sexually active and recurrence free breast cancer patients who had completed surgery, chemotherapy, and radiation therapy, $64 \%$ of the women reported an absence of sexual desire, $38 \%$ suffered from dyspareunia, and $42 \%$ experienced lubrication problems Vaginismus, brief intercourse and female orgasmic disorder were reported by $30 \%$ of the subjects. Thirty-six percent suffered from sexual dysfunction before treatment, which worsened in about $27 \%$, while in $49 \%$ of women sexual problems arose mainly after chemotherapy $(26 \%)$ or surgery $(12 \%)$. About one-half experienced changes in the relationship with their partner (Barni and Mondin 1997). In another study of breast cancer survivors, sexual dysfunction occurred more frequently in women who had received chemotherapy and in younger women who were no longer menstruating and depression was an important determinant of lower sexual desire, and survivors on antidepressants had greater problems with arousal and achieving orgasm. (Melisko et al., 2010) In a retrospective study of breast cancer among young females in Nigeria aged 40 years and 
below earlier reported by the author, $46 \%$ of the patients reported loss of libido (Ntekim et al., 2009). Another study revealed that women diagnosed at age $\leq 40$ years had significant less sexual interest after treatment than women over 40 years (Morrow, 2011).

Survivors with upper extremity lymphedema following breast cancer treatment also experience sexual dysfunction with upper extremity lymphedema as an additional predisposing factor. Sixty-nine women presenting for rehabilitation treatment for upper extremity lymphedema (UEL) were assessed by physical examination and validated selfreport assessment instruments measuring demographics, psychological distress, sexual functioning, social support, coping style, pain and functional status by Passik and colleagues (2007). Their analyses revealed that women with UEL had high levels of psychological distress, and high levels of sexual, functional and social dysfunction. There were no linear relationships between severity of UEL and levels of distress. Women with UEL in their dominant hand, however, had more distress and less overall sexual satisfaction than those with UEL in their non-dominant limb. Women with pain of any intensity were the most distressed, and had the most significant difficulties in psychological and physical functioning. Women with pain also perceived significantly less interpersonal support than those without pain. Virtually none were receiving pain treatment. An avoidant coping style and low perceived social support were significant correlates of psychological distress. The study concluded that UEL poses significant functional, social and sexual functioning problems in women following breast cancer treatment and that these patients may also benefit from psychological support and sexual therapy in addition to physical rehabilitation. There are therefore multiple predisposing factors for sexual dysfunction including preexisting sexual problems, negative sexual self-schemas, (cognitive generalizations regarding sexual aspects of the self; they represent a core component of one's sexuality) and normal age-related changes in sexual functioning. Physical consequences of treatment like absence of one breast, scar on the breast and upper extremity lymphedema are also important predisposing factors. Partners sexual problems and psychological reaction to the diagnosis of cancer are also contributory. Physiologic changes induced by chemotherapy are also important contributors. Induction of premature menopause can result in an estrogen deficiency state that increases the likelihood of hot flashes and poor vaginal lubrication that may contribute to sexual dysfunction (Kaplan, 1991)

\subsubsection{Sexual dysfunction and chemotherapy}

Compared to breast cancer women who were not treated with adjuvant chemotherapy, women treated with adjuvant chemotherapy are 5.7 times more likely to report vaginal dryness, 3 times more likely to report decreased libido, 5.5 times more likely to report dyspareunia, and 7.1 times more likely to report difficulty reaching orgasm.(Ganze etal., 1998). Chemotherapy therefore affects sexual functioning in women though the extent may vary according to different drug regimen and patients age.

\subsubsection{Sexual dysfunction and hormonal therapy}

It has been found that the incidence of vaginal dryness, dyspareunia, and loss of sexual interest in women taking Aromatase Inhibitors (AIs) was significant. These symptoms were particularly bothersome in women who experienced acute chemotherapy induced menopause as reported by Fallowfield et al., 2004. In the 5 year follow up in this study, vaginal discharge was less frequently bothersome with anastrozole than Tamoxifen $(1.2 \%$ 
vs. $5.2 \%)$ but vaginal dryness ( $18.5 \%$ vs. $9.1 \%)$, dyspareunia ( $17.3 \%$ vs. $8.1 \%)$, and reduced libido (34.0\% vs. $26.1 \%$ ) were all more common with anastrozole compared with Tamoxifen (Cella 2006). In the quality of life sub-study for the Intergroup Exemestane Study (IES), loss of libido was common and did not differ between groups receiving Tamoxifen for 5 years compared to those patients who switched over to exemestane after 2-3 years of Tamoxifen. There were no differences between the Tamoxifen or exemestane groups for vaginal dryness, discomfort with intercourse, and vaginal irritation (Fallowfield 2006).Even in patients without a diagnosis of breast cancer, hormonal therapies appear to have an impact on sexual function. Analysis of quality of life data from the Study of Raloxifene and Tamoxifen (STAR) prevention trial found that a higher percentage of women randomized to the Tamoxifen arm remained sexually active compared to women in the Raloxifene arm. Among sexually active participants, women randomized to the Raloxifene group experienced significantly more dyspareunia, greater difficulties with sexual interest, sexual arousal, and sexual enjoyment, but no significant difference in the ability to experience an orgasm (Land 2006).

Ganz et al (1999), found that among women 1 to 5 years post treatment, sexual problems (as measured by the CARES and the Watts Sexual Functioning Scale) were more common in women who had received chemotherapy. Lindley et al. (1998 as cited in Thors 2001), reported an interaction between age and chemotherapy in that the greatest negative change in sexual functioning (as measured by a series of questions that included items measuring sexual satisfaction and interest) occurred in premenopausal women who experienced chemotherapyinduced amenorrhea. Under oestrogen deprivation, with time, the mucosal and stromal tissues of the vagina, urethra, and trigone of the bladder undergo atrophy, resulting in decreased tissue elasticity and fluid secretion. This may lead to symptomatic vaginal dryness and irritation as well as dyspareunia. Oestrogen deprivation also leads to an elevation in vaginal $\mathrm{pH}$ which may increase the risk of vaginal and urinary tract infections.

\subsubsection{Interventions}

Study Instruments:

A number of study instruments have been used in sexual dysfunction studies in breast cancer survivors. The two more commonly used ones are Sexual History Form and the sexual summary subscale of the Cancer Rehabilitation Evaluation System (CARES). The Sexual History Form was developed by Schover and Jensen (1988, cited in Thors et al., 2001) and is composed of 27 multiple choice questions assessing sexual functioning, frequency, and satisfaction with sexual activity. This questionnaire has been standardized and norms from a healthy community sample are available for comparison purposes. The CARES is a quality-of-life instrument that includes an 8-item subscale measuring sexual interest and sexual dysfunction. The CARES has been shown to have adequate reliability and validity, and normative scores are available for cancer patients (Thors et al., 2001).

Other study questionnaires include Watts Sexual Functioning Questionnaire (442-13, sexual dysfunction subscale of The European Organization for Research and Treatment of Cancer [EORTC] QLQ-C30), Derogatis Sexual Functioning Inventory (DSFI), Arizona Sexual Experience Scale (ASEX) and Female Sexual Functioning Index (FSFI). Revised Dyadic Adjustment Scale can be used to assess partner relationship variables so also with Marital Satisfaction Inventory-Revised (MAI-R) (Stead 2003). 
Communication with women concerning sexual life is vital. Psychotherapy and behavioural approaches has been shown to be useful in managing these patients. Pharmacologic agents especially non estrogenic topical agents for specific problems like vaginal dryness are recommended. However a thorough assessment to determine which aspect of sexual function is affected can help in prescribing suitable approach to management. This can be done using more detailed study instruments. The commencement of pelvic floor muscle exercises, use of vaginal moisturizer to alleviate vaginal dryness and olive oil as lubricant during intercourse has been shown to improve sexual function in breast cancer survivors. (Juraskova 2011)

\subsection{Genito-urinary cancer survivors}

Survivors of cancer of the genito-urinary system do experience sexual dysfunction of which some are peculiar to affected organs. Some organs like the urinary bladder are closely related to sex organs and can directly affect sexual functions during the course of the disease and treatment. Post treatment effects like ovarian failure after chemotherapy and pelvic radiotherapy in females can have effects on sexual functions of survivors.

\subsubsection{Testicular cancer}

Testicular cancer is the most common cancer of young men in their 20s and 30s. Since the advent of effective multiagent cisplatinum-based chemotherapy, the majority of patients are cured. This disease occurs during the peak period of reproductive life and at a key time for career and family. As cured testicular patients have a long life expectancy, sexual function becomes an important issue. It has been found that hormonal dysfunction is frequent after the diagnosis of testicular cancer and treatment can have an additional detrimental effect. This can have a significant impact on the sexual life of the survivor and contribute to other health problems. Most patients, however, remain fertile though this can be affected by their treatment. Long-lasting sexual problems after therapy for testicular cancer are present in approximately one-fifth of patients undergoing treatment for testicular germ cell tumour. On the other hand, the majority of patients have not reported infertility or sexual dysfunctionrelated symptoms (Hartmann et al., 1999). In a study by Huddart and colleagues, the testicular module of the EORTC QLQ C-30 Questionnaire, which consists of six questions directed at sexual function and sexual satisfaction and two additional questions about masculinity and concerns about fathering children, was used. Overall sexual function from the analysis seemed to be satisfactory with $83 \%$ of patients expressing satisfaction in their sexual relationships with their partner with no differences between treatment groups. Compared to surveillance there was a tendency for treated groups to have less sexual activity and less interest in sex. This was only statistically significant for patients treated with chemotherapy and radiotherapy (CRT) and less interest in sex was of borderline significance for CRT and radiotherapy (RT). Additionally, radiotherapy treatment was associated with reduced sexual enjoyment compared with patients on surveillance (Huddart et al., 2005) The Derogatis Interview for Sexual Functioning-II Self-Report-Male questionnaire can also be used to assess sexual dysfunction in males (Greenfield et al.,2010).

\subsubsection{Prostate cancer}

Erectile dysfunction is common after prostatectomy because of the interference with the nerves. The extent being different with different methods of surgery as some have more nerve sparing effects than others. 
In comparison with prostatectomy, patients treated with external beam radiation report less long-lasting urinary symptoms, but more bowel side effects, with no difference in global quality of life. Sexual disorders are initially less important with external beam radiation but increase over time. Brachytherapy shows no sexual function preservation benefit relative to external beam radiation and may be less favourable with more urinary sequelae. The association of hormonal therapy and external beam radiation decreases the quality of life of the patients, with a negative impact on vitality, sexuality and increase urinary disorders. Intensity-modulated radiotherapy (IMRT) seems to better preserve the long-term digestive quality of life in comparison with conformal radiation therapy (Joly et al., 2010).

Radical surgical prostatectomy for cancer is performed by the perineal, retropubic, or transpubic routes. Surveys of patients undergoing either retropubic or perineal prostatectomy have reported comparable findings, with estimates of diminished erectile capabilities or complete erectile failure after surgery for $90 \%$ of the patients. The incidence of ejaculation difficulties with or without concomitant erectile failure is estimated as occurring for $78 \%$ of the retropubic and $100 \%$ of the perineal prostatectomy patients. If hormone therapy and/or orchiectomy are additionally used after either surgical procedure, virtually $100 \%$ of the patients experience erectile failure and ejaculation difficulties. These estimates are three to four times higher than those for patients treated for benign conditions with less extensive surgery (Andersen 1985). The sexual domain of the Expanded Prostate Cancer Index (EPIC) questionnaire can be used to assess prostate cancer survivors.

\subsubsection{Bladder cancer}

Early bladder cancer is treated by transurethral resection and there may be minimal sexual dysfunction. Cystectomy is associated with reduction in desire and erectile function in about $30 \%$ of male patients while sexual excitement and orgasm is impaired in women. (Anderson 1985) A comprehensive, disease specific measure of health related quality of life in patients with localised bladder cancer has been developed by Gilbert et al., (2010).

\subsection{Gynaecological cancer survivors}

Modalities of treatment comprising of surgery, chemotherapy, radiotherapy and hormonal therapy either single or in various combinations are used to treat gynaecological malignancies. All these modes have the potential to affect sexual functions of the patients. Gynaecological malignancies have the ability to affects a woman's sexual wellbeing primarily as the sexual reproductive organs are involved. Altered sexual functioning is the most affected aspect of quality of life of gynaecological cancer survivors occurring in $40-100 \%$ of patients compared to $19 \%-50 \%$ of the healthy outpatient population (Andersen, 1985).

\subsubsection{Cervical cancer}

The two modes of treatment for early disease, radical hysterectomy and radiation therapy, are equally common for early stage cervical cancer. Surgical treatment allows ovarian preservation for premenopausal women, but does cause vaginal shortening, which has contributed to coital discomfort (Andersen \& Hacker 1983). Radiation therapy destroys ovarian functioning and causes vaginal atrophy and stenosis. Dyspareunia from lack of lubrication, tenderness of the vagina, and post coital bleeding have been resultant problems. Comparable outcome with $29 \%$ and $33 \%$ of radiation and hysterectomy patients, respectively, reporting subsequent sexual difficulties have been reported (Andersen 1985). 
Some studies demonstrated that women with early stage cervical cancer receiving hysterectomy and radiotherapy suffered a number of short-term sexual difficulties such as dyspareunia, problems during intercourse and lack of sexual satisfaction, but that by 6 months after the surgery these problems had often reduced. However, some sexual difficulties persisted, in particular lack of sexual interest and lack of lubrication. In contrast, women with advanced, recurrent, or persistent cervical cancer experienced prolonged problems with vaginal lubrication, lack of orgasm, and lower frequency of intercourse, in addition to reduced sexual interest, throughout the 24 months post diagnosis (Stead 2004) The Female Sexual Function Index (FSFI) questionnaire and ALARM model are useful questionnaires to assess sexual function in these patients (Andersen 1990).

In a study by Lindau ST et al.( 2007 )sexual problems were significantly more prevalent among very long term (>25 years) survivors of cervical and vaginal cancers than in population-based comparison group. For example, the prevalence of dyspareunia (pain during intercourse) and difficulty lubricating were, respectively, nearly 7 and 3 times higher among survivors. Survivors were also significantly more likely than those in the population-based sample to exhibit complex sexual morbidity, defined as concurrent sexual problems in three or more of seven domains, and to report avoiding sex because of sexual problems (62\% versus $43 \%)$. In the same study, $62 \%$ of survivors reported that a doctor had never initiated a conversation about the effects of cancer or treatments for genital tract cancer on sexuality and Bivariate analysis revealed that a conversation with a physician about the sexual effects of genital tract cancer and cancer treatment is associated with significantly fewer sex morbidities. Some studies show that education on vaginal lubricants, moisturizers, and dilator use (as needed) can decrease the morbidity of vaginal atrophy (Carter et al., 2011).

\subsubsection{Vulval cancer}

Surgical treatment is commonly used for treating vulval carcinoma. This has some effects on sexual performance of the patients and various patterns of sexual dysfunction have been reported. A survey of 18 patients treated with wide local excision rather than vulvectomy for microinvasive disease indicated that all women continued to be orgasmic during sexual activity, in contrast to two radical vulvectomy patients who reported loss of orgasmic ability and dyspareunia. (Andersen 1985) A retrospective study of women who received radical surgery indicated discrepancies between the actual and the preferred frequency of sexual activities such as intercourse and a limited capacity for sexual arousal among these patients. Interestingly, orgasmic responsiveness is reported by women who had and who had not undergone clitoral excision at the time of vulvectomy (Thuesen et al., 1992). Another study has shown that more than half of women with vulval cancer experience sexual problems, with those women undergoing local vulval excision for vulval dysplasia experiencing the most problems. While these, in part, are related to anatomic changes, inadequate counselling and poor advice were contributing factors. A small study described how vulvectomy was associated with altered body image and arousal difficulties, and suggested that risk factors for sexual problems were age, depression, poor performance status, and preoperative sexual dysfunction. These findings demonstrate the need for appropriate counselling and advice for women with vulval cancer. (Green et al., 2000)

\subsubsection{Endometrial cancer}

Women with endometrial cancer are usually older and postmenopausal and their treatment often involves surgery plus radiotherapy and so surgery and radiation induced vaginal 
difficulties can occur. The pattern of sexual difficulties may be similar to those with cervical cancer of similar age group.

\subsubsection{Ovarian cancer}

Ovarian cancer is usually treated with a hysterectomy (including oophorectomy), and chemotherapy. Few of them also have adjuvant radiotherapy. These can all affect sexual functioning, through a decrease in oestrogen production resulting in vaginal atrophy and dryness. There can be hot flushes and loss of sexual interest resulting from changes in body and hormonal levels especially if the patients were pre menopausal prior to treatment. A study of 200 survivors of ovarian cancer showed that over $50 \%$ reported worsened sexual function (Stewart et al., 2001)

A cross-sectional study in 232 women with ovarian cancer showed that ovarian cancer is also associated with low sexual desire ( $47 \%$ reported no/little desire), vaginal dryness (experienced in $80 \%$ of women having sexual intercourse in the last month), dyspareunia (in $62 \%$ ), and problems with orgasm (in 75\%). This study also evaluated predictors of sexual activity and found that being married, being under 56 years, not receiving treatment, good selfesteem/body image, and length of time since end of treatment were all associated with being sexually active. This paper compared the findings of the research with studies in breast cancer and healthy postmenopausal women and concluded that although low desire, vaginal dryness, and dyspareunia occur in these other groups; the problems are more common and more severe in women with ovarian cancer. (Stead, 2004). A study of survivors of ovarian cancer found that about $80 \%$ of them who were sexually active before treatment reported vaginal dryness. This can lead to dyspareunia and subsequent fear of possible pain during vaginal penetration may contribute to the loss of interest in sex. (Carmack-Taylor et al., 2004).

EORTIC QLQ OV 28 is a useful questionnaire in assessing sexual dysfunction among ovarian cancer survivors.

The possible sexual problems caused by cancer treatment in females are presented in table 1 below.

\begin{tabular}{|c|c|c|c|c|c|c|}
\hline Treatment & $\begin{array}{l}\text { Low Sexual } \\
\text { Desire }\end{array}$ & $\begin{array}{l}\text { Less Vaginal } \\
\text { Moisture }\end{array}$ & $\begin{array}{l}\text { Reduced Vaginal } \\
\text { Size }\end{array}$ & $\begin{array}{c}\text { Painful } \\
\text { Intercourse }\end{array}$ & $\begin{array}{c}\text { Trouble } \\
\text { Reaching Orgasm }\end{array}$ & Infertility \\
\hline Chemotherapy & Sometimes & Often & Sometimes & Often & Rarely & Often \\
\hline Pelvic radiation therapy & Rarely & Often & Often & Often & Rarely & Often \\
\hline Radical hysterectomy & Rarely & Often ${ }^{b}$ & Often & Rarely & Rarely & Always \\
\hline Radical cystectomy & Rarely & Often & Always & Sometimes & Rarely & Always \\
\hline Abdominoperineal (A-P) resection & Rarely & Often ${ }^{b}$ & Sometimes & Sometimes & Rarely & Sometimes $^{b}$ \\
\hline $\begin{array}{l}\text { Total pelvic exenteration with vaginal } \\
\text { reconstruction }\end{array}$ & Sometimes & Always & Sometimes & Sometimes & Sometimes & Always \\
\hline Radical vulvectomy & Rarely & Never & Sometimes & Often & Sometimes & Never \\
\hline Conization of the cervix & Never & Never & Never & Rarely & Never & Rarely \\
\hline $\begin{array}{l}\text { Oophorectomy (removal of one tube and } \\
\text { ovary) }\end{array}$ & Rarely & Never $^{b}$ & Never $^{\mathrm{b}}$ & Rarely & Never & Rarely \\
\hline $\begin{array}{l}\text { Oophorectomy (removal of both tubes and } \\
\text { ovaries) }\end{array}$ & Rarely & Often ${ }^{b}$ & Sometimes $^{b}$ & Sometimes $^{b}$ & Rarely & Always \\
\hline Mastectomy or radiation to the breast & Rarely & Never & Never & Never & Rarely & Never \\
\hline Tamoxifen therapy for breast or uterine cancer & Sometimes & Often & Sometimes & Sometimes & Rarely & Always \\
\hline Androgen therapy & Never & Never & Never & Never & Never & Uncertain \\
\hline
\end{tabular}

b Vaginal dryness and size changes should not occur if one ovary is retained or if hormone therapy is given.

Table 1. Female sexual problems caused by cancer treatment. (Adapted from American Cancer Society Inc. 2009 as cited in Audette and Waterman 2010). 


\subsection{Gastro intestinal cancer survivors}

Survivors of gastrointestinal malignancies also experience sexual disorders. Although studies in most sites are not easily available, few reports show that survivors of these cancer site also experience sexual dysfunction.

\subsubsection{Colorectal cancer survivors}

Colorectal cancer is quite common all over the world including Europe and America. Surgical resection is an effective treatment modality for early diseases. The surgical approach differs according to the location of the tumour. Low lying tumours are located 0-5 $\mathrm{cm}$ from the anal verge and abdomino- perineal resection is the approach commonly used resulting in permanent colostomy. A review by Sprangers et al. (2003) noted that this operation disrupts nerve fibres associated with sexual function more in men than in women. It also noted that low or high anterior resection used in the treatment of tumours located more than $5 \mathrm{~cm}$ from the anal verge (lower or upper colon) which are sphincter sparing, also disrupts some nerves associated with sexual function especially if ultra low anastomosis are used. In a study on survivors after chemo-radiotherapy for rectal cancer using EORTIC QLQ-CR38, The scores for "sexual functioning" and "enjoyment" were low. Men had more sexual problems than females (62.5 vs. 25 mean scores respectively). (Tiv et al, .2010). Erectile dysfunction was also reported among men and the presence of colostomy was reported to further reduce sexual functioning in males but not in females.

Several retrospective studies of sexual functioning after excision of the rectum for cancer have been conducted. For men, estimates of sexual dysfunctions have ranged from $32 \%$ to $59 \%$ for sexual desire, from $28 \%$ to $76 \%$ for erectile difficulties and from $66 \%$ to $86 \%$ for ejaculation disruption (Andersen, 1985). Estimates for women from one investigation reported that $28 \%$ of the sample had reduced desire and $21 \%$ reported genital numbness or dyspareunia. (Kuchenhoff 1981 as cited in Andersen 1985)

Laparoscopic surgical techniques have been used in resection of colorectal cancers with reported equivalence in tumour clearance with conventional open techniques. It has additional advantage of less pain, reduced hospital stay and earlier return to normal function. In a retrospective assessment for rectal dysfunction in colorectal cancer patients who had laparoscopic resection, Aquah et al. (2002) reported that a significant difference in sexual function in males but not females was noted. Seven of the 15 sexually active men in the laparoscopic group reported impotence or impaired ejaculation while only one of the 22 patients in the open surgery group had such complain. $(\mathrm{P}=0.004)$. The study concluded that laparoscopic resection of colorectal cancer was associated with more sexual dysfunction than open surgical resection.

\subsubsection{Hepatocellular cancer (HCC)}

Patients with hepatocellular carcinoma also experience sexual dysfunction. In a study by Steel et al., (2005) comparing sexual dysfunction among hepatocellular cancer patients and chronic liver disease (CLD) patients, reported that with regards to the differences between HCC patients and those with CLD with respect to sexual problems, the rates of sexual morbidity were found to be higher in patients diagnosed with HCC for the majority of the sexual problems, including hypoactive sexual desire disorder ( $26 \%$ vs. $18 \%)$, sexual aversion disorder (18\% vs. $5 \%)$, male orgasmic disorder (13\% vs. $5 \%)$, premature ejaculation (17\% vs. $5 \%$ ), and dyspareunia ( $12 \%$ vs. $5 \%)$. The only disorder in which CLD patients reported a higher prevalence than HCC patients was male erectile disorder (21\% vs. $17 \%)$ Male patients 
had more sexual problems than the general population. The study also noted that co morbid conditions like hypertension, diabetes mellitus and cardio vascular diseases were more prevalent among HCC patients and medications for these conditions could add to their sexual problems.

\subsubsection{Anal cancer}

Majority of patients treated for anal cancer experience sexual dysfunction. A study using split course chemo radiotherapy for the treatment of anal cancer among 58 patients reported that fifty percent of patients maintained an interest in having sexual relations but $100 \%$ of male patients had difficulty maintaining an erection. Forty-four percent of men qualified the erectile dysfunction as severe (\# 4 on the scale: very much). Among women, $65 \%$ had no interest at all in sexual relations, $21 \%$ a little, and only $14 \%$ had a moderate interest. For those women who maintained an interest in having sexual relations, $50 \%$ reported having pain or discomfort during intercourse. The majority of the patients did not suffer from nonsatisfaction regarding their body or loss of masculinity or femininity in relation to their cancer or the treatment (Provencher et al., 2010).

\subsection{Haematological cancer survivors}

Survivors of haematological cancers including lymphoma do also experience sexual dysfunction especially those treated with bone marrow transplant. (Haematopoetic Stem Cell Transplant - HSCT). These patients usually receive cytotoxic chemotherapy and or whole body irradiation to suppress graft versus host reaction. Jean et al. (2009) in an extensive review of this aspect among survivors of HSCT noted that "these treatments impair the production of testosterone at least for the first year for males, and induce ovarian failure for most women. Effects are not solely gonadal. Treatments are known to permanently damage function of the hypothalamic-pituitary-gonadal axis. Luteinizing hormone (LH) is elevated in most female survivors and normal in most males. Follicle stimulating hormone is elevated in over $90 \%$ of females and most males. Most females have primary ovarian failure with consequent low endogenous oestrogen levels, and vaginal tissue atrophy is a risk. Chronic GVHD (Graft Versus Host Disease) may also contribute to vaginal introital stenosis and mucosal changes that contribute to dyspareunia, vaginal irritation, and increased sensitivity of genital tissues. Male sexual problems have been attributed to gonadal and cavernosal arterial insufficiency with resulting libido and erectile dysfunction." These reactions are mostly noted with alkylating agents class of cytotoxic drugs.

The lymphomas (Hodgkin's lymphoma [HL] and non-Hodgkin's lymphoma [NHL]) are among the most common cancers affecting men under 45 years. Survival rates are now excellent, but treatment is associated with a number of side effects including sexual dysfunction with potential implications for compromised quality of life (QoL). A study was carried out to address (i) the prevalence of sexual dysfunction among lymphoma survivors relative to the general population, survivors of other cancers, and in survivors of HL and NHL; and (ii) relationships between sexual functioning and disease and treatment, demographic, and psychological variables. Sexual function was found to be compromised relative to the general population, better than testicular cancer survivors, and worse than leukemia survivors. Depression was consistently associated with sexual dysfunction. There was evidence that chemotherapy, relapse, reduced testosterone levels, older age at survey, and worse physical QoL were associated with worse sexual function (Arden-Close et al., 2011). Another study found out that sexual problems were commonly reported by HL 
survivors, with $54.2 \%$ reporting decreased sexual activity and $41.4 \%$ reporting decreased interest. In the long term, this study did not show any difference in sexual function in long term survivors compared with the general population (Reclitis et al., 2010). However in another study on male lymphoma using Brief Sexual Function Index (BSFI) questionnaire, survivors had a mean age at survey of 47.4 years, the mean duration of follow-up was 14.8 years, and $79 \%$ lived in committed relationships. All BSFI domain scores decreased significantly with age. Lymphoma survivors also had low testosterone and/or elevated LH and had lower BSFI scores than survivors with normal gonadal hormones. Multivariate analyses showed that increasing age, more emotional distress, poor physical health, and low testosterone and/or elevated LH were significantly associated with reduced sexual function within the lymphoma group. Lymphoma survivors had significantly lower BSFI domain scores than did controls on erection, ejaculation, and sexual satisfaction (Kiserud et al., 2009). Erectile dysfunction has also been reported in $61 \%$ of lymphoma survivors assessed at least two years after treatment. (Aksoy et al., 2008). An earlier report found that chemotherapy for Hodgkin's disease produces ovarian failure in young women. The consequences of this are emotional distress, sexual dysfunction, and the disruption of families and friendships. These side effects of cytotoxic therapy had developed in 25 of 41 patients, among whom retrospective study was conducted (Chapman et al., 1979). Chemotherapy for Hodgkin's disease in that era however consisted of largely alkylating agents. Current combinations may not have such marked effects on ovarian function.

\subsection{Central nervous system survivors}

Survivors of brain tumours also experience sexual dysfunction. Neuroendocrine disturbances in anterior pituitary hormone secretion are common following radiation damage to the hypothalamic-pituitary (H-P) axis, the severity and frequency of which correlate with the total radiation dose delivered to the $\mathrm{H}-\mathrm{P}$ axis and the length of follow-up. The somatotropic axis is the most vulnerable to radiation damage and GH deficiency remains the most frequently seen endocrinopathy. With low radiation doses (<30 Gy) GH deficiency usually occurs in isolation in about $30 \%$ of patients, while with radiation doses of 30-50 Gy, the incidence of $\mathrm{GH}$ deficiency can reach $50-100 \%$ and long-term gonadotropin, TSH and ACTH deficiencies occur in 20-30, 3-9 and 3-6\% of patients, respectively. With higher dose cranial irradiation (>60 Gy) or following conventional irradiation for pituitary tumours (30-50 Gy), multiple hormonal deficiencies occur in 30-60\% after 10 years of follow-up. Precocious puberty can occur after radiation doses of $<30 \mathrm{~Gy}$ in girls only, and in both sexes equally with a radiation dose of 30-50 Gy. Hyperprolactinaemia, due to hypothalamic damage is mostly seen in young women after high dose cranial irradiation and is usually subclinical. H-P dysfunction is progressive and irreversible and can have an adverse impact on growth, body image, sexual function and quality of life. Regular testing is advised to ensure timely diagnosis and early hormone replacement therapy (Dalzy and Shalet, 2009). A prospective trial of the methods of sexual rehabilitation of 31 men with pituitary tumours has shown that therapy with testosterone and chorionic gonadotropin effectively corrects hypogonadism and sexual disorders. In insufficient efficacy, normalization of sexual function is achieved with tadalafil. Both methods of treatment had no negative effect on the size of the prostatic gland and PSA level except 2 patients with somatotropinoma on testosterone. In the course of chorionic gonadotropin treatment pituitary tumour increased in size in 3 patients (Rozhivanov \& Kurbatov 2010). There is a case report of a 39-year-old patient with a history of high-grade anaplastic astrocytoma who presented to the Sexual Health Program at the Memorial Sloan-Kettering Cancer Center complaining of vaginal 
discharge and several months of amenorrhea. Although the patient was administered extensive aggressive antineoplastic treatments, her disease rapidly progressed. She was found to have mild vaginal atrophy and had improved sexual function after treatment which consisted of intravaginal non-hormonal moisturizers and vaginal lubricants, counselling, and sexual education (Krychman et al.,2004).

\subsection{Survivors of sarcoma}

Sarcomas of soft tissues and bones/ cartilages are usually treated with surgery (if possible depending on the site), radiotherapy and sometimes with chemotherapy consisting of vincristine, cyclophosphamde, doxorubicine with or without actinomycine D. Chemotherapy especially cyclophosphamide has been reported to be associated with low sperm count and raised follicle stimulating hormones in males. Exposure before puberty was not found to be protective and infertility was associated with high doses of cyclophosphamide. (Kenny et al., 2001) Total sacrectomy and reconstruction for patients with osteosarcoma, chondrosarcoma, giant cell tumour and chordoma in the sacral region is associated with high degree of sexual dysfunction likely due to disruption of the nerves around the site. (Wuisman et al., 2000)

\subsection{Head and neck cancer survivors}

Survivors of head and neck cancers also have sexual dysfunction. In a study involving 55 participants, eighty-five percent showed interest in sex. Fifty-eight percent were satisfied with their current sexual partner and $49 \%$ were satisfied with their current sexual functioning. Majority reported arousal problems, 58\% did not participate in sexual intercourse, and 58\% had orgasmic problems. Most patients were not depressed. There was no correlation between sexual functioning and performance status or severity of disfigurement. Patients younger than 65 years of age had more advanced disease, lower performance status and significantly poorer sexual functioning; those older than 65 years were more satisfied with their sexual partner and current sexual functioning (Monga et al, 1997).

Study instruments used in studies among head and neck cancer patients include Derogatis Sexual Function Scale, EORTIC QLQ H\&N 37 sexual subscale

A quality of life studies among head and neck cancer survivors has been carried out at the Radiotherapy Department of The University College Hospital Ibadan Nigeria by the author. The aim of the study was to compare the quality of life pre treatment with quality of life at least 9 months post treatment of head and neck cancer patients seen at the centre. The materials and methods used included the assessment and evaluation of head and neck cancer patients that presented for treatment. All patients evaluated had histological confirmation of their conditions. Those with ECOG performance status greater than 2 or for palliative treatment were excluded as well as patients that were HIV positive. To study the sexuality component, The EORTIC H\&N QLQ 35 questionnaire was used. There are only 2 questions that relate to the sexuality domain in the instrument and these are questions:

29. Have you felt less interest in sex? And 30. Have you felt less sexual enjoyment? These were assessed on a 4 point Likert scale as follows:

$$
\begin{array}{cccc}
\text { Not at all } & \text { A little } & \text { Quite a bit } & \text { Very much } \\
1 & 2 & 3 & 4
\end{array}
$$

The questionnaires were administered before commencement of treatment and at least 9 months after treatment during follow up visits. 
A total of 100 patients were evaluated. The characteristics of the patients are presented in table 2 .

\begin{tabular}{ll}
\hline $\begin{array}{l}\text { Age group distributions } \\
\text { Age group (yrs) }\end{array}$ \\
16-25 & $13(13 \%)$ \\
$26-35$ & $9(9 \%)$ \\
$36-45$ & $20(20 \%)$ \\
$46-55$ & $16(16 \%)$ \\
$56-65$ & $24(24 \%)$ \\
$66-75$ & $0(0 \%)$ \\
$76-85$ & $18(18 \%)$ \\
Sex: & \\
Male & $58(58 \%)$ \\
Female & $42(42 \%)$ \\
Marital status: & \\
Single & $21(21 \%)$ \\
Married & $70(70 \%)$ \\
Widow/widower & $9(9 \%)$ \\
Level of Education: & \\
Primary & $6(6 \%)$ \\
Secondary & $38(38 \%)$ \\
Tertiary & $31(31 \%)$ \\
None & $25(25 \%)$ \\
\hline
\end{tabular}

Table 2. Head and Neck Quality of Life (Sex) studies : Patients' characteristics. (N=100)

The overall mean age was 49.86 years with a range of $18-85$ years and Standard Deviation $(S D)=17.48$. Mean age for males $=51.59$ years, range $=19-85$ years and $S D=16.93$ while mean age for females $=47.60$ years with a range of $18-85$ years and SD $=18.39$. The pretreatment and post treatment scores are presented in table 3

\begin{tabular}{lcccc}
\hline & $\begin{array}{c}\text { Pre- treatment } \\
\text { scores }\end{array}$ & $\begin{array}{c}\text { post treatment } \\
\text { scores }\end{array}$ & Std Deviation & p-value \\
Overall (mean) & 38.6 & 49.8 & 18.00 & 0.00 \\
$\quad$ Male & 35.0 & 46.2 & 31.38 & \\
Female & 42.2 & 53.9 & 28.70 & 0.21 \\
Stage & & 44.0 & 29.67 & \\
$1 / 11$ & & 50.3 & 30.56 & 0.47 \\
$111 / 1 \mathrm{~V}$ & & & & \\
Disease Sites & 40 & 44 & & \\
Oral cavity & 49 & 58 & & \\
Nasopharynx: & 50 & 53 & & \\
Oropharynx: & 36 & 50 & & \\
Larynx: & 44 & 60 & & \\
Sino-nasal region & 32 & 36 & & \\
Salivary gland: & 15 & 41 & & \\
Thyroid gland & 15 & 50.5 & \\
\hline
\end{tabular}

Table 3. Head and Neck Quality of Life ( Sex) Scores (N=100) 
These results show that there were reduction in sexual functioning in all the patients after treatment for head and neck cancers and these were noticed with all cancer sites. Survivors of cancers of the Sino-nasal region experienced the highest sexual problems followed by those with laryngeal cancers among the core head and neck cancer patients. Survivors of thyroid cancer however had the highest score of sexual dysfunction and it is better considered separately as endocrine cancers since hypothyroidism can result in sexual dysfunction. Patients with advanced diseases (stages $111 \& 1 \mathrm{~V}$ ) experienced more sexual problems than those with early diseases (stages $1 \& 11$ ).[P value 0.47] This is similar to earlier reports by Monga et al.,(1997) who reported poorer sexual function among patients with advanced disease which was more in those 65 years and above. The result also shows that the effect was more on females than males (P value 0.21 ). This may probable be due to the use of chemotherapy which may have more effects on the hormonal status of the female patients. Some chemotherapy agents affect the ovaries leading to reduction in the amount of circulating oestrogen. This leads to reduced sexual functions. Ovarian failure occurs most often in women who are above 35 years of age after chemotherapy (Schover, 2008).

The reported changes in sexuality is important because the mean age of these patients was 49 years which means that these patients are relatively young and therefore sexually active, as this is an important social aspect for many of them.

This analysis gives an indication that these patients have sexual issues following treatment. These issues need to be addressed by care givers. More detailed study focussing on sexuality of survivors using questionnaires that can evaluate specific aspects of sexual function is required for better assessment and management of survivors of head and neck cancers in this environment.

\subsection{Lung cancer survivors}

Sexual problems exist among survivors of lung cancer. A report noted that sexual concerns were common, with $52 \%$ of patients reporting at least mild sexual concerns and were stable. Sexual concerns were significantly associated with physical and emotional symptoms. Particularly strong relationships were found between sexual concerns and shortness of breath and emotional distress. Age moderated the relationship between both fatigue and shortness of breath and sexual concerns. Gender moderated the relationship between emotional distress and sexual concerns. Self-reported sexual concerns were noted to be common in people with lung cancer, are stable, and are related significantly to physical and emotional symptoms. Age and gender influenced the distress associated with sexual symptoms in this population.(Reese et al., 2011)

\subsection{Management of sexual dysfunction}

It is important that sexual issues be looked into among cancer patients especially after treatment. During the course of the disease, lots of issues like anxiety concerning the disease and its treatment, financial issues, employment related issues and other social issues may affect sexual health of the patients. Those who have completed their treatment will be free from many other co-founding problems and sexual issues will come to the fore. These have to be addressed as part of the patients' management. It is also pertinent to note that these issues vary in intensity with respect to duration of survival hence periodic reassessment needed for necessary adjustments in pattern of care. 


\subsubsection{Assessment}

Cancer survivors should be assessed for sexual dysfunction before treatment and as soon as they are clinically stable. It is important to know the pre treatment sexual functioning of the individual as this varies from person to person. This baseline information will also enable the health personnel to assess the degree of variation ascribable to the disease and its treatment. Anxiety and depression associated with the illness should be identified and managed before addressing sexual concerns. There is also need to distinguish cancer patients with sexual difficulties and concomitant psychosocial stressors (e.g., financial, familial, occupational, marital). These latter difficulties could disrupt the range, frequency, enjoyment, or importance of sexual activity for cancer patients as they sometimes do for healthy individuals.) from those without additional stressors, allowing more specific etiologic associations to be identified

Discussions on survivors sexual health can be commenced using some tools like:-

PLISSIT model-Permission, Limited Information, Specific Suggestions and Intensive Therapy. This model involves four stages to guide the assessment and treatment of sexual dysfunction. The first stage, permission, involves providing the patient with an opportunity to discuss sexual problems or concerns. Limited information involves the provision of general information about the sexual problem and options for intervention. Specific suggestions would include detailed discussions about treatment options and techniques that could be used to improve sexual activity. Intensive Therapy usually involves referral to a specialist. This model can be used to systematically guide the healthcare professional through the evaluation of sexual dysfunction and the provision of information. (Stead 2004) ALARM model- Activity, Libido, Arousal, Resolution, Medical information. Communication has to be initiated by the health care personnel with the patients concerning the above aspects of their sexual lives in order to establish possible areas of intervention. PLEASURE model -Partner, Lovemaking, Emotions Attitude, Symptoms, Understanding, Reproduction Energy.

BETTER model- Bring up the topic, Explain that sexuality is an important aspect of quality of life and should be discussed, Tell patients that there are resource s available to address concerns or problems, Timing is important, offer discussions and let them know you are available anytime, Educate patients and families how treatment can impact sexuality, Record discussions, assessment, interventions and outcomes (Audette \& Waterman 2010).

These tools can be applied for general screening of patients for sexual dysfunction and it is recommended that this assessment should be done periodically to monitor the patients. Detailed diagnostic tools could then be applied in those with established problems for more specific diagnosis based on disease site and patients characteristics. A list of some other tools that can be used to assess various aspects of sexual dysfunction is provided in table 4 ..

\subsubsection{Treatment}

Some physical therapy like exercises can help in the treatment of some forms of sexual dysfunction as part of general well being resulting from exercise. Specific exercises like pelvic floor exercises can promote relaxation and help in relieving dyspareunia following treatment of some gynaecological malignancies. Intercourse should be encouraged at least three times per week following pelvic irradiation in women. Alternatively, vaginal dilators of fingers can be used at least three times per week for ten minutes to keep the vaginal canal patent. This is also useful towards follow up examinations (Borduka \& Sun 2006). Pharmacological agents like non steroidal lubricants for women are also available for those experiencing vaginal dryness. Psychological therapy especially by specialists can improve 
the situation. Hormonal replacements may be useful especially in some hormone associated conditions like following treatment for pituitary tumours and other endocrine malignancies.

\begin{tabular}{|c|c|c|}
\hline Name of Questionnaire & Author(s) & $\begin{array}{l}\text { Original } \\
\text { language }\end{array}$ \\
\hline Arizona Sexual Experience Scale & Gelenberg, A. & English \\
\hline $\begin{array}{l}\text { Brief Index for Sexual Functioning for } \\
\text { women (BISF-F) }\end{array}$ & Rosen ,R. & English \\
\hline Brief Sexual Function Index (BSFI) & O'Leary, M. & English \\
\hline $\begin{array}{l}\text { Changes in Sexual Functioning } \\
\text { Questionnaire (CSFQ)- F \& M } \\
\text { Components }\end{array}$ & Clayton, A & English \\
\hline $\begin{array}{l}\text { Derogatis Index for Sexual Functioning } \\
\text { (DISF) M \& F }\end{array}$ & Derogatis, L & English \\
\hline $\begin{array}{l}\text { Erectile dysfunction Inventory of } \\
\text { Treatment Satisfaction (EDITS) }\end{array}$ & Altof S Et al., for Pfizer Inc & English \\
\hline $\begin{array}{l}\text { Erectile Dysfunction Quality of Life ED } \\
\text { EQOL }\end{array}$ & Mac Donagh & English \\
\hline Erectile Dysfunction Question (EDQ) & Araujo, A. & English \\
\hline Female Sexual Desire Profile (FSDP) & Nillson, A. & English \\
\hline Female Sexual Distress Scale (FSDS) & Derogatis, L. & English \\
\hline $\begin{array}{l}\text { Female Sexual Distress Scale } \\
\text { (FSDS)- Revised } 2005\end{array}$ & Derogatis, L. & English \\
\hline $\begin{array}{l}\text { Female Sexual Encounter Profile - } \\
\text { adapted (FSEPa) }\end{array}$ & Ferguson D. & English \\
\hline $\begin{array}{l}\text { Female Sexual Function Questionnaire } \\
\text { (FSFQ) }\end{array}$ & Quirk, F & English \\
\hline Female Sexual Function Index (FSFI) & Rosen ,R \& Ferguson D & English \\
\hline $\begin{array}{l}\text { International Index of Erectile Function } \\
\text { (IERF) }\end{array}$ & Rosen, R for Pfizer Inc & English \\
\hline $\begin{array}{l}\text { International Index of Erectile Function } \\
\text { (IERF)- Partner Diary }\end{array}$ & Rosen ,R. For Pfizer Inc & English \\
\hline Inventory of Treatment satisfaction (ITS) & Althof et al. & English \\
\hline Mc coy Sexuality Questionnaire (MFSQ) & Mc Coy, N. & English \\
\hline $\begin{array}{l}\text { MOS Sexual Function Module } \\
\text { (MOS-SEXUAL) }\end{array}$ & Ware Dr. & English \\
\hline Psychosexual Daily Questionnaire (PDQ) & Wang, C. & English \\
\hline Sexual Activity Questionnaire (SEXACQ) & Fallowfield L & English \\
\hline Sexual Function Index (SFI) & O'Leary & English \\
\hline $\begin{array}{l}\text { Sexual Life Quality Questionnaire } \\
\text { (SLQQ) }\end{array}$ & Lass, S. & English \\
\hline Sexual Satisfaction Module (SEXTES) & Testa, M. & English \\
\hline
\end{tabular}

Table 4. Specific Questionnaires: Sexuality. Adapted from Mapi Institute (n.d.) 


\section{Conclusion}

The prevalence of sexual dysfunction among cancer survivors is high and the extent varies according to years of survival, disease site, age and sex of the patients. It should therefore be borne in mind that almost all oncology patients have sexual issues. There is need for improvement in the routine assessment of sexual functions among cancer survivors. To enhance this, training on basic assessment techniques including communication should be undergone by all those who partake in the care of cancer patients. There is also need for increased training in management of sexual issues and management techniques should be improved upon through further research for effectiveness.

\section{Acknowledgement}

I wish to acknowledge the assistance of Dr Adamu Bojude, Departmant of Radiation Oncology, University College Hospital Ibadan Nigeria for his assistance on the study on sexual dysfunction of Head and Neck Cancer survivors seen at the department of Radiation Oncology, University College Hospital Ibadan Nigeria.

\section{References}

Alfano, C.; Smith, A.; Irwin, M.; Bowen D.; Sorensen B.; Reeve B \& Tiernan A (2007). Physical activity,long term symptoms and physical health related quality of life among breast cancer survivors: A prospective analysis. Journal of Cancer Survival Vol.1 No. 2 (Dec 2007)pp. 116-128.

Aksoy S, Harputluoglu H, Kilickap S, Dincer M, Dizdar O, Akdogan B, Ozen H, Erman M \& Celik I (2007). Erectile dysfunction in successfully treated lymphoma patients. SupportCare Cancer. 2008 Mar; Vol.16 No.3 (Mar 2008): pp.291-297.

Andersen L, \& NF (1983). Psychosexual adjustment following pelvic exenteration. Obstet Gynecol. No (1983) pp.61:331-338

Andersen L.(1990) How cancer affects sexual functioning. Oncology (Williston Park). Vol.4 No.6 ( June1990) pp:81-88

Andersen, L. (1985).Sexual Functioning Morbidity Among Cancer Survivors: Current Status and Future Research Directions Cancer. Vol. 55 No.8 (April 1985)pp 1835-1842

Aqua H, Jayne D, Eu K \& Seow-Choen K (2002). Bladder and sexual dysfunction following laparascopically assisted and conventional open meso rectal resection for cancer. British Journal of Surgery vol. 892002 pp 1551-1556.

Arden-Close E, Eiser C\& Pacey A. (2011) Sexual Functioning in Male Survivors of Lymphoma: A Systematic Review. J Sex Med. No 16 (Feb2011) pp.1000-.1111

Audette C and Waterman J. The Sexual Health of Women after Gynaecologic Malignancy (2010) Journal of Midwifery and Womens Health Vol 55 No. 4 ( July 2010) pp 357-362.

Barni, S. \& Mondin, R. (1997). Sexual dysfunction in treated breast cancer patients. Annals of Oncology Vol. 8, (1997) pp. 149-153

Bober, S. Reclitis , C. Campbell, E., Park, E. Kutner J. Najita J. \& Diller , 1. (2009). Caring for cancer survivors. Cancer Vol.115 No. S18 (Sept 2009) pp. 4409-4418. 
Bonini-Colmano M.; Molnar S.; Salvano L.; Molina G.; Arevelo M.; Di Marco P.; Rizzi M. \& Dibersarsky C. (2007) Sexual dysfunction in patients with cancer. Journal of Clinical Oncology 2007 ASCO Annual meeting proceedings Part 1 Vol 25 No. 18 S (June supplement 2007) Abstract 19653.

Borduka D \& Sun C (2006). Sexual function after gynaecological cancer . Obstetrics Gynaeco clin of $N$ Am No $33(, 2006)$ pp.621-630

Bukovic D.; Fajdic, J.; Argovic Z.; Kaufmann M.; Hojsak I. \& Stanceric T (2005). Sexual dysfunction in breast cancer survivors. Onkologie vol. 28 No. 1 (2005) pp. 29-34

Carmack-Taylor 1, Basen-Engquist k, Shinn E and Bodurka D (2004) Predictors of sexual functioning in ovarian cancer patients. Journal of Clinical Oncology No 22 (2004) pp. 881-889

Carter J, Goldfrank D, Schover LR (2011). Simple strategies for vaginal health promotion in cancer survivors. J Sex Med. Vol.8 No.2 (Feb 2011) pp.549-559

Cella D, Fallowfield L, Barker P, Cuzick J, Locker \&, Howell A (2006). Quality of life of postmenopausal women in the ATAC ("Arimidex", tamoxifen, alone or in combination) trial after completion of 5 years' adjuvant treatment for early breast cancer. Breast Cancer Res Treat. No.100 (2006) pp.273-84

Chapman R, Sutcliffe S \& Malpas J (1979) Cytotoxic-induced ovarian failure in Hodgkin's disease Effects on sexual function. JAMA. .26; Vol.242 No.17 (Oct 1979):pp.18821884.

Darzy K\&, Shalet S (2009) . Hypopituitarism following Radiotherapy Revisited Endocr Dev No.15 (2009) pp 1-24.

Fallowfield L, Cella D, Cuzick J, Francis S, Locker G \& Howell A. (2004). Quality of life of postmenopausal women in the Arimidex, Tamoxifen, Alone or in Combination (ATAC) Adjuvant Breast Cancer Trial. J Clin Oncol. Vol 22, (2004) pp. 4261-71

Fallowfield LJ, Bliss JM, Porter LS, et al (2006). Quality of life in the intergroup exemestane study: a randomized trial of exemestane versus continued tamoxifen after 2 to 3 years of tamoxifen in postmenopausal women with primary breast cancer. J Clin Oncol. No.249 (2006) PP. 910-917s

Ganz PA, Desmond KA, Belin TR, et al (1999). Predictors of sexual health in women after a breast cancer diagnosis. Journal of Clinical Oncolology No. 17.(1999) pp.2371-2380

Ganz, P.; Rowland J.; Desmond, K.; Meyerowitz B.; \& Wyatt G (1998). Life after breast cancer: Understanding women's health related quality of life and sexual functioning. Journal of Clinical Oncology No. 16 (1998) pp 501-514

Ganz PA, Coscarelli A, Fred C, et al (1996) Breast cancer survivors: psychosocial concerns and quality of life. Breast Cancer Res Treat. No.38 (1996) pp.183-199.

Gilbert, S. Dunn, R B. Hollenbeck, J. Montie, J. Lee, C, Wood D. \& Wei J. (2010). Development and Validation of the Bladder Cancer Index:A Comprehensive, Disease Specific Measure of Health Related Quality of Life in Patients With Localized Bladder Cancer Journal of Urology Vol.183 No 5 (2010) pp. 1764-1769

Green M, Naumann R, Elliot M, et al(2000).: Sexual dysfunction following vulvectomy. Gynecol Oncol 2000, No.77 (2000) pp.73-77. 
Greenfield M, Walters J, Coleman R, Hancock B, Snowden J, Shalet S, DeRogatis L \&, Ross R. (2010) Quality of life, self-esteem, fatigue, and sexual function in young men after cancer: a controlled cross-sectional study. Cancer. Vol.116 No.6 (March 2010) pp.1592-601.

Hartmann,J. Albrecht C, Schmoll H, Kuczyk M, Kollmannsberger C \& Bokemeyer C (1999) . Long-term effects on sexual function and fertility after treatment of testicular cancer. British Journal of Cancer Vol 80 No.5/6 (1999), pp. 801-807

Joly F.; Degrendel A.; Guizard A.;(2010). Quality of life after radiotherapy for prostate cancer. Cancer Radiother. 2010 Oct Vol.14 No.6-7 Oct (2010) pp.519-25.

Kenney L, Laufer M, Grant F, Grier H\& Diller L.(2001).High risk of infertility and long term gonadal damage in males treated with high dose cyclophosphamide for sarcoma during childhood. Cancer. 2001 Feb Vol.91 No.3 (Feb 2001):pp.613-621.

Kiserud C, Schover L, Dahl A, Fossay A, BiA ,ro T, Loge J, Holte H, Yuan Y, \& Fossay S (2009). Do male lymphoma survivors have impaired sexual function? J Clin Oncol. Vol.27 No.35 (Dec 2009) pp. 6019-26.

Krychman M, Amsterdam A, Carter J, Castiel M \& DeAngelis L. Brain cancer and sexual health: a case report. Palliat Support Care. Vol.2 No.3 (Sep 2004): pp.315-318.

Land SR, Wickerham DL, Costantino JP, et al.(2006) Patient-reported symptoms and quality of life during treatment with tamoxifen or raloxifene for breast cancer prevention: the NSABP Study of Tamoxifen and Raloxifene (STAR) P-2 trial. Jama. Vol.295 (2006) pp.2742-2751

Lindau, S. Anderson, D \& Gavrilova, N (2007) Sexual Morbidity in Very long-term Survivors of Vaginal and Cervical Cancer: A Comparison to National Norms Gynecol Oncol. Vol 106 No.2 (August 2007) pp. 413-418.

Lindley C,Vasa S, Sawyer WT, et al. (1998) Quality of life and preferences for treatment following systemic adjuvant therapy for early stage breast cancer. Journal of Clinical Oncology. No 16 (1998) pp.1380-1387.

Ntekim, A.; Nuhu F. \& Campbell O (2009). Breast cancer in young females in Ibadan Nigeria. African Health Sciences Vol. 9 No. 4 (2009) pp 242-246

Melisko M.;bGoldman M.\& Rugo S. (2010). Amelioration of sexual adverse effects of the early breast cancer patient. Journal of Cancer Survival Vol.4 No. 3 (Sept 2010)pp. 247255

Mapi Institute (n.d.) Sexuality in Specific Questionnaires Accessed June 26, 2011, <Available http. www. Mapi-institute.com/ component/content/article/6-list/135- specificquestionnaires-sexuality

Monga U, Tan G, Ostermann H, Monga TN(1997.) .Sexuality in head and neck cancer patients Arch Phys Med Rehab Vol.78 No.3: (Mar 1997) pp.298-304

Morrow P .(2011). Long term effects of the diagnosis and treatment of breast cancer upon young breast cancer survivors. Journal of Clinical Oncology Vol. 29. No. 15S Part 1 of 11 (May 2011) p 560S.

Ofman, S. (1995). Preservation of function in genitor-urinary cancers: psychosexual and psychosocial issues. Cancer Investigations, vol.13.No. 1 (1995) pp. 125-131 
Park,, E.; Bober, S.; Campbell, E.; Recklitis, C.; Kutner, J.\& Diller, L (2009 ) General Internist Communication about Sexual Function with Cancer Survivors J Gen Intern Med. No 24 Suppl 2 (Nov.2009) pp. 407-411.

Passik S, Newman M.; Brennan M. \& Tunkel R. (1995) Predictors of psychological distress, sexual dysfunction and physical functioning among women with upper extremity lymphedema related to breast cancer Psycho Oncology Vol 4 No.4,(1995)pp. 255-263

Recklitis C, Sanchez Varela V, Ng A, Mauch P \& Bober S (2010). Sexual functioning in longterm survivors of Hodgkin's lymphoma. Psycho -oncology. Vol.19 No.11 (Nov 2010):pp.1229-1233.

Reese J, Shelby R \& Abernethy A. (2011).Sexual concerns in lung cancer patients: an examination of predictors and moderating effects of age and gender. Support Care Cancer. 2011 Jan;Vol.19 No.1 (Jan 2011):pp.161- 165.

Rozhivanov R\&, Kurbatov D (2010). Sexual function rehabilitation of men with pituitary tumors. Urologiia Vol. 4 No. 48 (Jul-Aug.2010) pp 50-53.

Sawyna Provencher S; Oehler, C.Lovertu S, Jolicoeur, M Fortin, B. \& Donath D. Quality of life and tumor control after short split-course chemoradiation for anal canal carcinoma Radiat Oncol. 2010; Vol 5: No.41(May 2010) pp 1000-1186.

Schover L (2008) Premature ovarian failure and its consequences: Vasomotor symptoms, sexuality and fertility. J Clin Oncol No.26,(2008) pp.753-758.

Speer, J.; Hillenberg, B.; Sugrue, D.; Blacker, C.; Kresge C.; Decker, V.; Zakalik D. \& Decker, D. (2005) Study of sexual functioning determinants in breast cancer survivors. The Breast Journal Vol. 11 No. 6 (2005) pp. 440-4471.

Sprangers M, Taal B, Aaronson N and Velde, A (2007). Quality of life in colorectal cancer. Stoma versus non stoma patients. Diseases of Colon and Rectum, vol 38,No.4 ( 2007) pp. 361-369

Stead, L. (2003) .Sexual dysfunction after treatment for gynaecologic and breast malignancies. Current Opinion in Obstetrics \& Gynecology. Vol. 15 No. 1 (Feb 2003) pp 57-61

Stead L (2004). Sexual function after treatment for gynaecological malignancy Curr Opin Oncol No 16 (2004) pp :492-495.

Steel J.;Hess S,; Tunke L .;\& Carr B Chopra K (2005). Sexual Functioning in Patients with Hepatocellular Carcinoma. Cancer Vol 104 No 10 ( Nov 2005 ) pp 2234-2243

Thors C.; Broeckel, J.; \& Jacobson P. (2001). Sexual functioning in breast cancer survivors. Cancer Control Vol. 8 No. 5 (Oct 2001) pp.442-448

Thuesen B, Andreasson B,\& Bock JE: (1992) Sexual function and somapsychic reactions after local excision of vulval intra-epithelial neoplasia. Acta Obstet Gynaecol Scand, No.71 (1992) pp.126-128.

Tiv M, Puyraveau M, Mineur L, Calais G, Maingon P, Bardet E, Mercier M \& Bosset J. (2010) Long-term quality of life in patients with rectal cancer treated with preoperative (chemo)-radiotherapy within a randomized trial. Cancer Radiother.;Vol.14 No.6-7 ( Oct 2010) pp.530-534. 
Wuisman P, Lieshout O, Sugihara S \& van Dijk M.(2000). Total sacrectomy and reconstruction: oncologic and functional outcome. Clin Orthop Relat Res. 2000 Dec;No.381 (Dec 2000):pp.192-203.

Yi, J. \& Syrjala, K.(2009) Sexuality after Hematopoietic Stem Cell Transplantation Cancer J. Vol.15 No.1 (2009) pp. 57-64. 


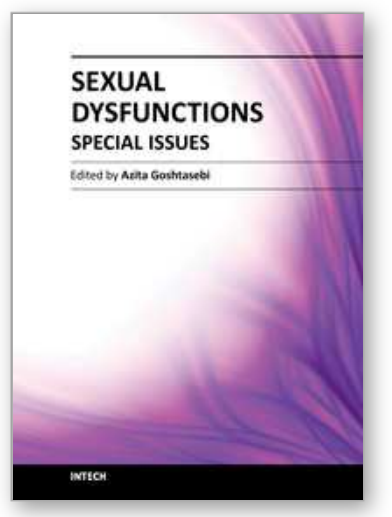

\author{
Sexual Dysfunctions - Special Issues \\ Edited by Dr. Azita Goshtasebi
}

ISBN 978-953-307-859-5

Hard cover, 128 pages

Publisher InTech

Published online 22, December, 2011

Published in print edition December, 2011

Sexual dysfunctions have recently recognized as one of the major public health problems. This book enhances our scientific understanding of sexual function and dysfunction from different perspectives. It presents evidence-based interventions for sexual dysfunctions in difficult medical situations such as cancer, and gives a valuable overview of recent experimental researches on the topic. Published in collaboration with InTech Open Access Publisher, this imperative work will be a practical resource for health care providers and researchers who are involved in the study of sexual health.

\title{
How to reference
}

In order to correctly reference this scholarly work, feel free to copy and paste the following:

Atara Ntekim (2011). Sexual Dysfunction Among Cancer Survivors, Sexual Dysfunctions - Special Issues, Dr. Azita Goshtasebi (Ed.), ISBN: 978-953-307-859-5, InTech, Available from:

http://www.intechopen.com/books/sexual-dysfunctions-special-issues/sexual-dysfunction-among-cancersurvivors

\section{INTECH}

open science | open minds

\section{InTech Europe}

University Campus STeP Ri

Slavka Krautzeka 83/A

51000 Rijeka, Croatia

Phone: +385 (51) 770447

Fax: +385 (51) 686166

www.intechopen.com

\section{InTech China}

Unit 405, Office Block, Hotel Equatorial Shanghai

No.65, Yan An Road (West), Shanghai, 200040, China

中国上海市延安西路65号上海国际贵都大饭店办公楼 405 单元

Phone: +86-21-62489820

Fax: +86-21-62489821 
(C) 2011 The Author(s). Licensee IntechOpen. This is an open access article distributed under the terms of the Creative Commons Attribution 3.0 License, which permits unrestricted use, distribution, and reproduction in any medium, provided the original work is properly cited. 